\title{
Penentuan Lokasi Stup Menggunakan Pembobotan Rank Order Centroid (ROC) dan Simple Additive Weighting (SAW)
}

\author{
I Made Arya Budhi Saputra \\ Institut Teknologi dan Bisnis STIKOM Bali \\ e-mail:aryabudhi@stikom-bali.ac.id \\ Diajukan: 23 September 2020; Direvisi: 30 Oktober 2020; Diterima: 12 November 2020
}

\begin{abstract}
Abstrak
Salah satu sumber daya alam yang dimiliki Indonesia adalah produk hasil hutan bukan kayu yang di mana saat ini menjadi salah satu prioritas pengembangan dari Kementerian Lingkungan Hidup dan Kehutanan. Komoditas yang menjadi unggulan dari produk hasil bukan kayu adalah madu. Walaupun mudah dalam pemeliharaan, namun jumlah produksi dari madu Trigona di daerah Kerandangan belum cukup optimal hal tersebut dikarenakan para kelompok tani saat ini masih mengalami kebingungan dalam menentukan lokasi stup (rumah lebah). Sering kali para petani salah dalam menentukan lokasi stup, yang menyebabkan lebah tidak dapat menghasilkan madu secara maksimal. Penggunaan metode Rank Order Centroid (ROC) pada penelitian ini untuk membantu kelompok tani dalam pemberian bobot kriteria berdasarkan tingkat kepentingannya. Selanjutnya bobot tersebut digunakan dalam perhitungan Simple Additive Weighting (SAW). Di mana penggunaan metode ini dirasa cukup mudah untuk dipahami para kelompok tani. Konsep dasar metode ini adalah mencari penjumlahan terbobot dari rating kinerja pada setiap alternatif di semua atribut. Hal ini dapat membantu kelompok tani dalam menentukan lokasi stup.
\end{abstract}

Kata kunci: Madu, Trigona, Stup, ROC, SAW.

\begin{abstract}
One of the natural resources owned by Indonesia is non-timber forest products which are currently one of the development priorities of the Ministry of Environment and Forestry. The main commodity of non-wood products is honey. Even though it is easy to maintain, the production amount of Trigona honey in this area is not optimal because the farmer groups are currently still experiencing confusion in decide the location of the bee house. Often the farmers are wrong in decide the location of the bee house, which causes the bees to not produce honey maximally. The use of the Rank Order Centroid (ROC) method in this study was to assist farmer groups in assigning weight to criteria based on their level of importance. Furthermore, these weights are used in the calculation of Simple Additive Weighting (SAW). Where the use of this method is considered easy enough for the farmer groups to understand. The basic concept of this method is to find the weighted sum of the performance ratings for each alternative across all attributes. This can assist farmer groups in determining the location of the bee house.
\end{abstract}

Keywords: Honey, Trigona, bee house, ROC, SAW.

\section{Pendahuluan}

Sumber daya alam negara Indonesia yang sangat melimpah menjadikan Indonesia menjadi salah satu negara yang penghasil sumber daya alam terbesar di dunia. Salah satu sumber daya alam yang dimiliki Indonesia adalah produk hasil hutan bukan kayu yang di mana saat ini menjadi salah satu prioritas pengembangan dari Kementerian Lingkungan Hidup dan Kehutanan. Komoditas yang menjadi unggulan dari produk hasil bukan kayu adalah madu [1].

Madu Trigona merupakan madu yang cukup banyak dikonsumsi oleh masyarakat pada saat ini karena khasiatnya tersebut. Madu ini cukup mudah dalam pemeliharaan dan tidak membutuhkan keahlian khusus dalam proses panen, hasil madu yang tidak tergantung pada musim pembungaan. Di daerah Kerandangan (Lombok barat) terdapat sebuah kelompok tani yang membudidayakan madu ini [2].

Walaupun mudah dalam pemeliharaan, namun jumlah produksi dari madu Trigona di daerah ini belum cukup optimal hal tersebut dikarenakan para kelompok tani saat ini masih mengalami kebingungan dalam menentukan lokasi stup (rumah lebah). Sering kali para petani salah dalam menentukan lokasi stup, yang menyebabkan lebah tidak dapat menghasilkan madu secara maksimal. 
Berdasarkan hasil diskusi dengan para pakar, tentunya pembuatan stup memiliki sejumlah kriteria. Sejumlah kriteria tersebut adalah jumlah jenis bunga di sekitar lokasi, curah hujan, jumlah pestisida di sekitar lokasi, tersedia sumber pakan non bunga, dan jumlah pesaing di sekitar lokasi.

Jumlah jenis bunga di sekitar bunga menjadi salah satu kriteria karena bunga menghasilkan serbuk sari merupakan makanan utama dari lebah untuk menghasilkan madu. Curah hujan menjadi kriteria karena apabila curah hujan terlalu tinggi madu yang dihasilkan terlalu encer. Jumlah pestisida yang terlalu tinggi menjadi terlalu berbahaya bagi lebah. Sumber pakan non bunga juga menjadi pakan alternatif bagi lebah. Jumlah pesaing yang dimaksud adalah jumlah kelompok tani lain di sekitar lokasi [2].

Penggunaan metode Rank Order Centroid (ROC) pada penelitian ini untuk membantu kelompok tani dalam proses pemberian bobot kriteria berdasarkan tingkat kepentingannya. Selanjutnya bobot tersebut digunakan dalam perhitungan metode Simple Additive Weighting (SAW). Di mana penggunaan metode ini dirasa cukup mudah untuk dipahami para kelompok tani. Cara kerja dari metode SAW adalah pencarian penjumlahan terbobot dari rating kinerja pada setiap alternatif di semua atribut. Di mana nilai yang tertinggi direkomendasikan sebagai yang terbaik. Kombinasi dari kedua metode ini dapat membantu kelompok tani dalam menentukan lokasi stup.

\section{Metode Penelitian}

\subsection{Sistem Pendukung Keputusan}

Dalam Frieyadie, Kusrini menyatakan sistem merupakan kumpulan elemen yang saling berkaitan yang bertanggung jawab memproses masukan (input) sehingga menghasilkan keluaran (output). Sistem pendukung keputusan merupakan sistem informasi interaktif yang menyediakan informasi pemodelan, dan pemanipulasian data [3].

Menurut Alter dalam Lusiana dkk, Sistem pendukung keputusan digunakan untuk membantu pengambilan keputusan dalam situasi semi terstruktur dan situasi tidak terstruktur, di mana tidak seorang pun tahu secara pasti bagaimana keputusan seharusnya dibuat [4]. Menurut Turban dalam Lusiana, dkk sistem pendukung keputusan adalah suatu bentuk Computer Base Information System (CBIS) yang interaktif, fleksibel, dan secara khusus dikembangkan untuk mendukung penyelesaian masalah dari manajemen yang tidak terstruktur untuk memperbaiki pembuatan keputusan [4].

Terdapat sejumlah karakteristik pada sebuah sistem pendukung keputusan. Menurut Turban dalam Rahmat, dkk terdapat sebanyak 14 karakteristik dan kapabilitas kunci dari sistem pendukung keputusan yang digambarkan pada gambar di bawah ini [5].

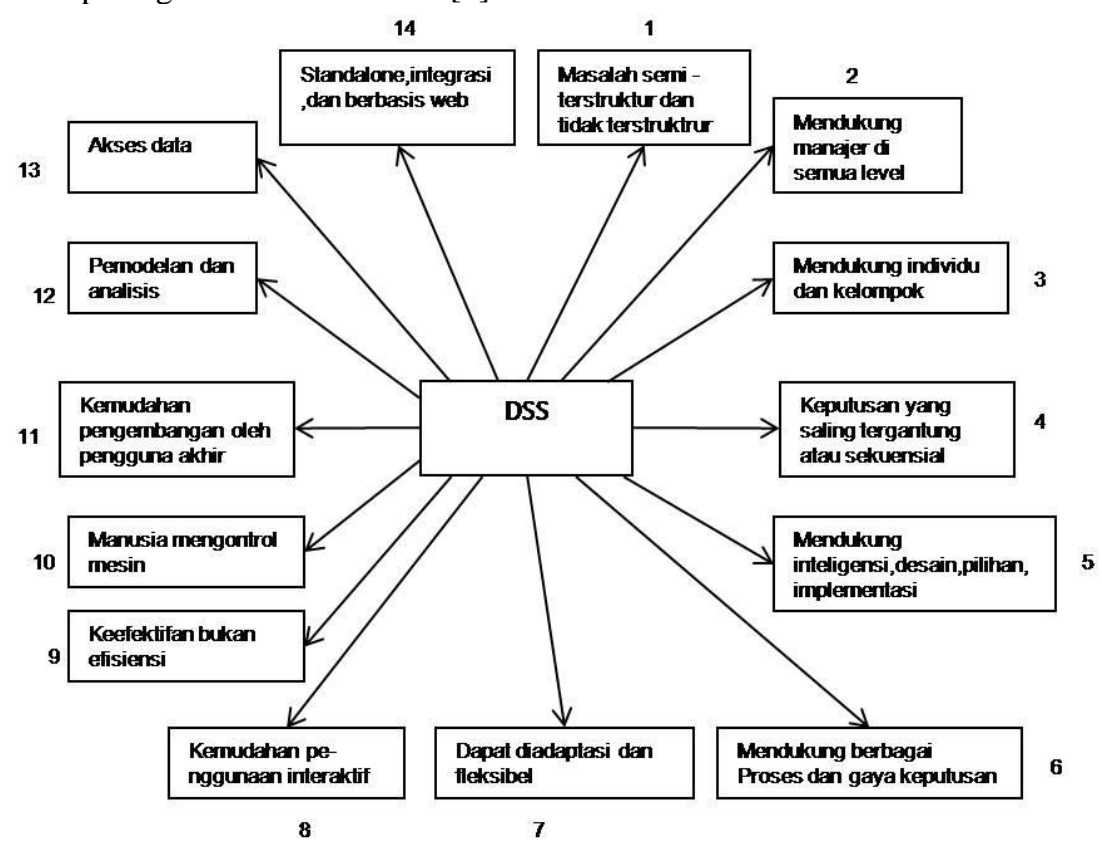

Gambar 1. Karakteristik dan kapabilitas SPK.

Penjelasan dari karakteristik dan kapabilitas tersebut adalah:

1. Sistem pendukung keputusan mendukung untuk proses pengambilan keputusan, terutama pada situasi tak terstruktur maupun semi terstruktur. 
2. Dapat digunakan untuk semua level manajerial, dari puncak pimpinan hingga pimpinan di setiap bidang.

3. Dapat digunakan untuk kelompok maupun individu.

4. Dapat digunakan untuk semua keputusan independen maupun sekuensial.

5. Mendukung di semua fase proses pengambilan keputusan: inteligensi, desain, pilihan, dan implementasi.

6. Mendukung di berbagai gaya dan proses pengambilan keputusan.

7. Memiliki kemampuan sistem beradaptasi dengan cepat

8. User-friendly,

9. Meningkatkan efektivitas dalam pengambilan keputusan (akurasi, timelines, kualitas) dari pada efisiensi (biaya).

10.Decision maker memiliki kuasa penuh di setiap langkah proses pengambilan keputusan dalam memecahkan masalah.

11. End user dapat melakukan pengembangan dan perubahan sistem secara sederhana.

12. Penggunaan model dalam menganalisis pengambilan keputusan.

13. Tersedianya akses untuk berbagai sumber data, format, dan tipe, mulai dari sistem informasi geografi (GIS) sampai sistem berorientasi objek.

14. Dapat berdiri sendiri atau standalone untuk pengambil keputusan di satu lokasi atau dapat didistribusikan ke seluruh organisasi.

\subsection{Rank Order Centroid (ROC)}

Konsep dasar dari metode Rank Order Centroid (ROC) adalah memberikan bobot berdasarkan tingkat kepentingan dari kriteria. Biasanya dibentuk dengan pernyataan "Kriteria 1 lebih penting dari kriteria 2, yang lebih penting dari kriteria 3" dan seterusnya hingga kriteria ke n [6].

Jika,

Maka,

$$
\mathrm{C}_{\mathrm{r} 1} \geq \mathrm{C}_{\mathrm{r} 2} \geq \mathrm{C}_{\mathrm{r} 3} \geq \mathrm{C}_{\mathrm{r} 4} \geq \ldots \geq \mathrm{C}_{\mathrm{m}}
$$

$$
\mathrm{W}_{1} \geq \mathrm{W}_{2} \geq \mathrm{W}_{3} \geq \mathrm{W}_{4} \geq \ldots \geq \mathrm{W}_{\mathrm{n}}
$$

Selanjutnya, jika k merupakan banyaknya kriteria, maka:

$$
\begin{aligned}
\mathrm{W}_{1} & =\frac{1+\frac{1}{2}+\frac{1}{3}+\cdots+\frac{1}{k}}{k} \\
\mathrm{~W}_{2} & =\frac{0+\frac{1}{2}+\frac{1}{3}+\cdots+\frac{1}{k}}{k} \\
\mathrm{~W}_{3} & =\frac{0+0+\frac{1}{3}+\cdots+\frac{1}{k}}{k} \\
\mathrm{~W}_{\mathrm{k}} & =\frac{0+\cdots+0+\frac{1}{k}}{k}
\end{aligned}
$$

Secara umum pembobotan ROC dapat dirumuskan sebagai berikut [5]:

$$
\mathrm{W}_{\mathrm{k}}=\frac{1}{k} \sum_{i=1}^{k}\left(\frac{1}{i}\right)
$$

\subsection{Simple Additive Weight (SAW)}

Menurut Fishburn dan MacCrimmon dalam Frieyadie mengemukakan bahwa penjumlahan terbobot merupakan istilah lain dari metode Simple Additive Weight (SAW). Konsep dasar dari metode ini adalah mencari penjumlahan terbobot dari rating kinerja pada setiap alternatif pada semua atribut [3].

$$
\begin{gathered}
\mathrm{R}_{\mathrm{ij}}=\frac{X_{i j}}{\operatorname{Max} X_{i j}} \mathrm{Jika} \mathrm{j} \text { adalah atribut keuntungan (benefit) } \\
\mathrm{R}_{\mathrm{ij}}=\frac{\operatorname{Min} X_{i j}}{X_{i j}} \mathrm{Jika} \mathrm{j} \text { adalah atribut biaya (cost) } \\
\mathrm{V}_{\mathrm{i}}=\sum_{j=1}^{n} W_{j} R_{i j}
\end{gathered}
$$


Alternatif yang memiliki nilai akhir tertinggi merupakan alternatif yang terpilih.

\subsection{Stup (Rumah Lebah)}

Stup atau rumah lebah dibuat agar lebah aman dan nyaman betah tinggal disarangnya dan memudahkan pemanenan produk lebah. Karena itu bahan dan bentuknya pun berbeda-beda di setiap wilayah [7].

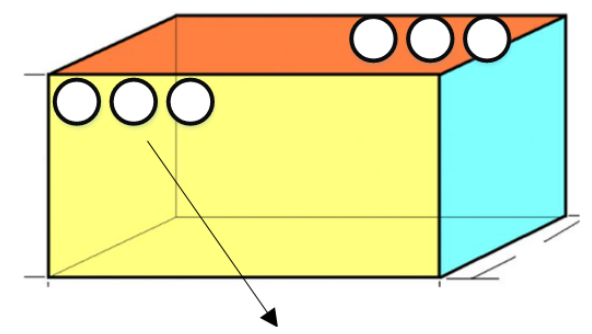

Lubang $0,5 \mathrm{~cm}$ dan jarak antar lubang $5 \mathrm{~cm}$

Gambar 2. Kotak stup (tampak samping).

\section{Hasil dan Pembahasan}

\subsection{Kriteria}

Terdapat 5 kriteria yang digunakan pada penelitian ini, 5 kriteria tersebut dijabarkan dalam Tabel 1 di bawah ini:

Tabel 1. Tabel kriteria.

\begin{tabular}{cl}
\hline No & \multicolumn{1}{c}{ Nama Kriteria } \\
\hline 1 & Jumlah jenis bunga di sekitar lokasi \\
\hline 2 & Curah hujan (mm) \\
\hline 3 & Jumlah pestisida di sekitar lokasi (g/ha) \\
\hline 4 & Tersedia sumber pakan non bunga \\
\hline 5 & Jumlah pesaing di sekitar lokasi. \\
\hline
\end{tabular}

\subsection{Alternatif}

Terdapat 5 alternatif lokasi yang digunakan pada penelitian ini, di mana pada Tabel 2 dijabarkan lokasi beserta nilai alternatif pada masing-masing kriteria yang dijabarkan sebelumnya pada Tabel 1.

Tabel 2. Tabel alternatif.

\begin{tabular}{ccccccc}
\hline No & $\begin{array}{c}\text { Nama } \\
\text { Alternatif } \\
\text { Lokasi }\end{array}$ & $\begin{array}{c}\text { Jumlah jenis } \\
\text { bunga di sekitar } \\
\text { lokasi (Ben) }\end{array}$ & $\begin{array}{c}\text { Curah hujan } \\
(\mathbf{m m}) \\
(\text { Ben) }\end{array}$ & $\begin{array}{c}\text { Jumlah pestisida di } \\
\text { sekitar lokasi(g/ha) } \\
\text { (Cost) }\end{array}$ & $\begin{array}{c}\text { Tersedia sumber } \\
\text { pakan non bunga } \\
\text { (Ben) }\end{array}$ & $\begin{array}{c}\text { Jumlah pesaing } \\
\text { di sekitar lokasi } \\
\text { (Cost) }\end{array}$ \\
\hline 1 & Lokasi A & 5 & 1500 & 100 & 3 & 2 \\
\hline 2 & Lokasi B & 3 & 2000 & 78 & 2 & 1 \\
\hline 3 & Lokasi C & 4 & 2750 & 87 & 1 & 1 \\
\hline 4 & Lokasi D & 6 & 1250 & 90 & 2 & 3 \\
\hline 5 & Lokasi E & 2 & 2500 & 110 & & 2 \\
\hline
\end{tabular}

\subsection{Perhitungan Bobot Menggunakan Metode Rank Of Centroid (ROC)}

Berdasarkan hasil wawancara dengan kelompok tani, kriteria diurutkan sebagai berikut:

Tabel 3. Tabel urutan kriteria.

\begin{tabular}{cl}
\hline No Urut & \multicolumn{1}{c}{ Nama Kriteria } \\
\hline 1 & Jumlah jenis bunga di sekitar lokasi \\
\hline 2 & Tersedia sumber pakan non bunga \\
\hline 3 & Curah hujan (mm) \\
\hline 4 & Jumlah pestisida di sekitar lokasi (g/ha) \\
\hline 5 & Jumlah pesaing di sekitar lokasi. \\
\hline
\end{tabular}

Dihitung menggunakan metode Rank Order Centroid, maka bobot dari masing-masing kriteria diperoleh sebagai berikut: 
Tabel 4. Hitung bobot dengan metode ROC.

\begin{tabular}{clc}
\hline No Urut & \multicolumn{1}{c}{ Nama Kriteria } & Perhitungan Rank Order Centroid (ROC) \\
\hline 1 & Jumlah jenis bunga di sekitar lokasi & $\frac{1+\frac{1}{2}+\frac{1}{3}+\frac{1}{4}+\frac{1}{5}}{5}=\frac{2.2833}{5}=0,456$ \\
\hline 2 & Tersedia sumber pakan non bunga & $\frac{0+\frac{1}{2}+\frac{1}{3}+\frac{1}{4}+\frac{1}{5}}{5}=\frac{1.2833}{5}=0,256$ \\
\hline 3 & Curah hujan (mm) & $\frac{0+0+\frac{1}{3}+\frac{1}{4}+\frac{1}{5}}{5}=\frac{0.7833}{5}=0,156$ \\
\hline 4 & Jumlah pestisida di sekitar lokasi $(\mathrm{g} / \mathrm{ha})$ & $\frac{0+0+0+\frac{1}{4}+\frac{1}{5}}{5}=\frac{0.45}{5}=0,09$ \\
\hline 5 & Jumlah pesaing di sekitar lokasi. & $\frac{0+0+0+0+\frac{1}{5}}{5}=\frac{0.2}{5}=0,04$ \\
\hline
\end{tabular}

\subsection{Perhitungan Menggunakan Metode SAW}

\subsubsection{Normalisasi}

Selanjutnya, proses dilanjutkan menggunakan metode Simple Additive Weight (SAW), di mana proses selanjutnya dalam metode ini adalah proses normalisasi matriks yang disajikan dalam tabel di bawah ini.

Tabel 5. Perhitungan nilai normalisasi.

\begin{tabular}{|c|c|c|c|c|c|c|}
\hline No & $\begin{array}{l}\text { Nama } \\
\text { Alternatif } \\
\text { Lokasi }\end{array}$ & $\begin{array}{c}\text { Jumlah jenis } \\
\text { bunga di sekitar } \\
\text { lokasi (Ben) }\end{array}$ & $\begin{array}{c}\text { Curah hujan } \\
(\mathbf{m m}) \\
(\text { Ben }) \\
\end{array}$ & $\begin{array}{c}\text { Jumlah pestisida di } \\
\text { sekitar lokasi(g/ha) } \\
\text { (Cost) }\end{array}$ & $\begin{array}{l}\text { Tersedia sumber } \\
\text { pakan non bunga } \\
\text { (Ben) }\end{array}$ & $\begin{array}{c}\text { Jumlah pesaing } \\
\text { di sekitar lokasi } \\
\text { (Cost) }\end{array}$ \\
\hline 1 & Lokasi A & $\frac{5}{6}=0.83$ & $\frac{1500}{2750}=0.54$ & $\frac{78}{100}=0.78$ & $\frac{3}{3}=1$ & $\frac{1}{2}=0.5$ \\
\hline 2 & Lokasi B & $\frac{3}{6}=0.72$ & $\frac{2000}{2750}=0.72$ & $\frac{78}{78}=1$ & $\frac{2}{3}=0.66$ & $\frac{1}{1}=1$ \\
\hline 3 & Lokasi C & $\frac{4}{6}=0.67$ & $\frac{2750}{2750}=1$ & $\frac{78}{87}=0.89$ & $\frac{1}{3}=0.33$ & $\frac{1}{1}=1$ \\
\hline 4 & Lokasi D & $\frac{6}{6}=1$ & $\frac{1250}{2750}=0.45$ & $\frac{78}{90}=0.86$ & $\frac{1}{3}=0.33$ & $\frac{1}{2}=0.5$ \\
\hline 5 & Lokasi E & $\frac{2}{6}=0.33$ & $\frac{2500}{2750}=0.90$ & $\frac{78}{110}=0.70$ & $\frac{2}{3}=0.66$ & $\frac{1}{3}=0.3$ \\
\hline
\end{tabular}

\subsubsection{Normalisasi Dikalikan Dengan Bobot}

Proses dilanjutkan dengan mengalikan antara hasil normalisasi pada Tabel 5 dengan bobot yang telah diperoleh pada Tabel 4. Hasil dari perkalian kedua tabel tersebut terlihat pada Tabel 6 di bawah ini.

Tabel 6. Normalisasi dikalikan bobot.

\begin{tabular}{|c|c|c|c|c|c|c|}
\hline No & $\begin{array}{c}\text { Nama } \\
\text { Alternatif } \\
\text { Lokasi } \\
\end{array}$ & $\begin{array}{c}\text { Jumlah jenis } \\
\text { bunga di sekitar } \\
\text { lokasi (Ben) }\end{array}$ & $\begin{array}{c}\text { Curah hujan } \\
\text { (mm) } \\
\text { (Ben) } \\
\end{array}$ & $\begin{array}{c}\text { Jumlah pestisida di } \\
\text { sekitar lokasi(g/ha) } \\
\text { (Cost) }\end{array}$ & $\begin{array}{c}\text { Tersedia sumber } \\
\text { pakan non bunga } \\
\text { (Ben) }\end{array}$ & $\begin{array}{c}\text { Jumlah pesaing } \\
\text { di sekitar lokasi } \\
\text { (Cost) }\end{array}$ \\
\hline 1 & Lokasi A & $\begin{array}{c}0.83 * 0.456 \\
=0.38\end{array}$ & $\begin{array}{c}0.54 * 0.256 \\
=0.139\end{array}$ & $\begin{array}{c}0.78 * 0.156 \\
=0.121\end{array}$ & $\begin{array}{c}1 * 0.09 \\
=0.09\end{array}$ & $\begin{array}{l}0.5 * 0.04 \\
=0.02\end{array}$ \\
\hline 2 & Lokasi B & $\begin{array}{c}0.72 * 0.456 \\
=0.228\end{array}$ & $\begin{array}{c}0.72 * 0.256 \\
=0.186\end{array}$ & $\begin{array}{c}1 * 0.156 \\
=0.156\end{array}$ & $\begin{array}{c}0.66 * 0.09 \\
=0.06\end{array}$ & $\begin{array}{c}1 * 0.04 \\
=0.04\end{array}$ \\
\hline 3 & Lokasi C & $\begin{array}{c}0.67 * 0.456 \\
=0.304\end{array}$ & $\begin{array}{c}1 * 0.256 \\
=0.256\end{array}$ & $\begin{array}{c}0.89 * 0.156 \\
=0.139\end{array}$ & $\begin{array}{c}0.33^{*} 0.09 \\
=0.03\end{array}$ & $\begin{array}{c}1 * 0.04 \\
=0.04\end{array}$ \\
\hline 4 & Lokasi D & $\begin{array}{c}1 * 0.456 \\
=0.456\end{array}$ & $\begin{array}{c}0.45 * 0.256 \\
=0.116\end{array}$ & $\begin{array}{c}0.86 * 0.156 \\
=0.135\end{array}$ & $\begin{array}{c}0.33 * 0.09 \\
=0.03\end{array}$ & $\begin{array}{c}0.5 * 0.04 \\
=0.02\end{array}$ \\
\hline 5 & Lokasi E & $\begin{array}{c}0.33 * 0.456 \\
=0.152\end{array}$ & $\begin{array}{c}0.90 * 0.256 \\
=0.232\end{array}$ & $\begin{array}{c}0.70 * 0.156 \\
=0.110\end{array}$ & $\begin{array}{c}0.66 * 0.09 \\
=0.06\end{array}$ & $\begin{array}{c}0.3 * 0.04 \\
\quad=0.01\end{array}$ \\
\hline
\end{tabular}

\subsubsection{Penjumlahan Nilai Seluruh Kriteria di Tiap Alternatif}

Proses selanjutnya pada metode Simple Additive Weight (SAW) adalah menjumlahkan nilai seluruh kriteria di tiap alternatif. Hasil penjumlahan dijabarkan pada tabel 7 dibawah ini. 
Tabel 7. Penjumlahan seluruh kriteria di tiap alternatif.

\begin{tabular}{|c|c|c|c|c|c|c|c|}
\hline No & $\begin{array}{c}\text { Nama } \\
\text { Alternatif } \\
\text { Lokasi }\end{array}$ & $\begin{array}{c}\text { Jumlah jenis } \\
\text { bunga di } \\
\text { sekitar } \\
\text { lokasi (Ben) } \\
\end{array}$ & $\begin{array}{c}\begin{array}{c}\text { Curah } \\
\text { hujan } \\
\text { (mm) } \\
\text { (Ben) }\end{array} \\
\end{array}$ & $\begin{array}{c}\text { Jumlah } \\
\text { pestisida di } \\
\text { sekitar lokasi } \\
\text { (g/ha) (Cost) } \\
\end{array}$ & $\begin{array}{c}\text { Tersedia } \\
\text { sumber } \\
\text { pakan non } \\
\text { bunga (Ben) } \\
\end{array}$ & $\begin{array}{c}\text { Jumlah } \\
\text { pesaing di } \\
\text { sekitar lokasi } \\
\text { (Cost) }\end{array}$ & Nilai Total \\
\hline 1 & Lokasi A & 0.38 & 0.139 & 0.121 & 0.09 & 0.02 & $\begin{array}{c}0.38+0.139+0.121+0.09+ \\
0.02=0.751\end{array}$ \\
\hline 2 & Lokasi B & 0.228 & 0.186 & 0.156 & 0.06 & 0.04 & $\begin{array}{c}0.228+0.186+0.156+0.06+ \\
0.0=0.670\end{array}$ \\
\hline 3 & Lokasi C & 0.304 & 0.256 & 0.139 & 0.03 & 0.04 & $\begin{array}{c}0.304+0.256+0.139+0.03+ \\
0.04=0.769\end{array}$ \\
\hline 4 & Lokasi D & 0.456 & 0.116 & 0.135 & 0.03 & 0.02 & $\begin{aligned} 0.456+0.116 & +0.135+0.03+ \\
0.02 & =0.757\end{aligned}$ \\
\hline 5 & Lokasi E & 0.152 & 0.232 & 0.110 & 0.06 & 0.01 & $\begin{array}{c}0.152+0.232+0.110+0.06+ \\
0.01=0.568\end{array}$ \\
\hline
\end{tabular}

Proses dilanjutkan dengan menghitung proses pemeringkatan, hal ini bertujuan untuk mengetahui alternatif yang memperoleh nilai akhir tertinggi yang direkomendasikan untuk lokasi stup. Tabel 8 merupakan hasil pemeringkatan dari kelima alternatif tersebut.

Tabel 8. Penjumlahan seluruh kriteria di tiap alternatif.

\begin{tabular}{ccc}
\hline Rank & Nama Alternatif Lokasi & Nilai Total \\
\hline 1 & Lokasi C & 0.769 \\
\hline 2 & Lokasi D & 0.757 \\
\hline 3 & Lokasi A & 0.751 \\
\hline 4 & Lokasi B & 0.670 \\
\hline 5 & Lokasi E & 0.568 \\
\hline
\end{tabular}

\section{Kesimpulan}

Berdasarkan hasil pembahasan di atas, dapat ditarik sejumlah kesimpulan sebagai berikut:

1. Lokasi C memperoleh nilai akhir tertinggi menggunakan metode Rank Order Centroid dan Simple Additive Weighting.

2. Cara pengukuran pada tiap kriteria belum dijelaskan secara mendetail.

3. Jumlah alternatif dan kriteria yang masih minim, belum memaparkan kelebihan dari kombinasi kedua metode.

\section{Daftar Pustaka}

[1] B. P. Kehutanan aek nauli, Panduan Manual Budidaya Lebah Madu. 2014.

[2] Balitbangtek, Panduan Singkat Budidaya Breeding Lebah Trigona sp., no. 7. 2018.

[3] Frieyadie, "PENERAPAN METODE SIMPLE ADDITIVE WEIGHT (SAW) DALAM SISTEM PENDUKUNG KEPUTUSAN PROMOSI KENAIKAN JABATAN,” J. pilar nusa mandiri, vol. XII, no. 1 , pp. 37-45, 2016.

[4] L. Kristiyanti and A. Sugiharto, "SISTEM PENDUKUNG KEPUTUSAN PEMILIHAN PENGAJAR LES PRIVAT UNTUK SISWA LEMBAGA BIMBINGAN BELAJAR DENGAN METODE AHP," J. Masayrakat Inform., vol. 4, no. 7, pp. 39-47, 2007.

[5] R. Tullah, A. R. Mariana, and D. Baskoro, "Sistem Pendukung Keputusan Pemilihan Calon Penerima Beasiswa Bidikmisi Menggunakan Metode AHP dan TOPSIS Pada STMIK Bina Sarana Global,” J. Sisfotek Glob., vol. 8, no. 2, 2018.

[6] N. Astiani, D. Andreswari, and Y. Setiawan, "Aplikasi Sistem Pendukung Keputusan Tanaman Obat Herbal Untuk Berbagai Penyakit Dengan Metode Roc (Rank Order Centroid) Dan Metode Oreste Berbasis Mobile Web," J. Inform., vol. 12, no. 2, 2016, doi: 10.21460/inf.2016.122.486.

[7] E. Ramadhan, H. C. H. Siregar, and K. Kuntadi, "Modifikasi Ventilasi pada Tutup Stup Koloni Lebah Madu (Apis Mellifera) Terhadap Produksi Propolis," J. Ilmu Produksi dan Teknol. Has. Peternak., vol. 4, no. 1, pp. 212-217, 2016, doi: 10.29244/jipthp.4.1.212-217. 